\title{
CORRECTION
}

View Article Online

View Journal I View Issue

(2) Click for updates

Cite this: RSC Adv., 2016, 6, 26883

DOI: $10.1039 /$ c6ra90027e

www.rsc.org/advances

\section{Correction: Nano-micellar Zn(Cys) 2 complex mimics the chloroperoxidase active site}

\author{
Mohammad M. Akbarzadeh*
}

Correction for 'Nano-micellar $\mathrm{Zn}(\mathrm{Cys})_{2}$ complex mimics the chloroperoxidase active site' by Mohammad M. Akbarzadeh et al., RSC Adv., 2016, 6, 12081-12083.

The author regrets that in the ESI of the original article the data presented in Fig. 3S, and consequently the thermodynamic parameters listed in Table 3S, are incorrect because the ITC plot does not contain a subtraction for the buffer. Corrected versions of Fig. $3 \mathrm{~S}$ and Table $3 \mathrm{~S}$ are presented herein, of particular note are the recalculated values for $N$, the $K_{\mathrm{a}}, \Delta H, \Delta G$ and $\Delta S$.

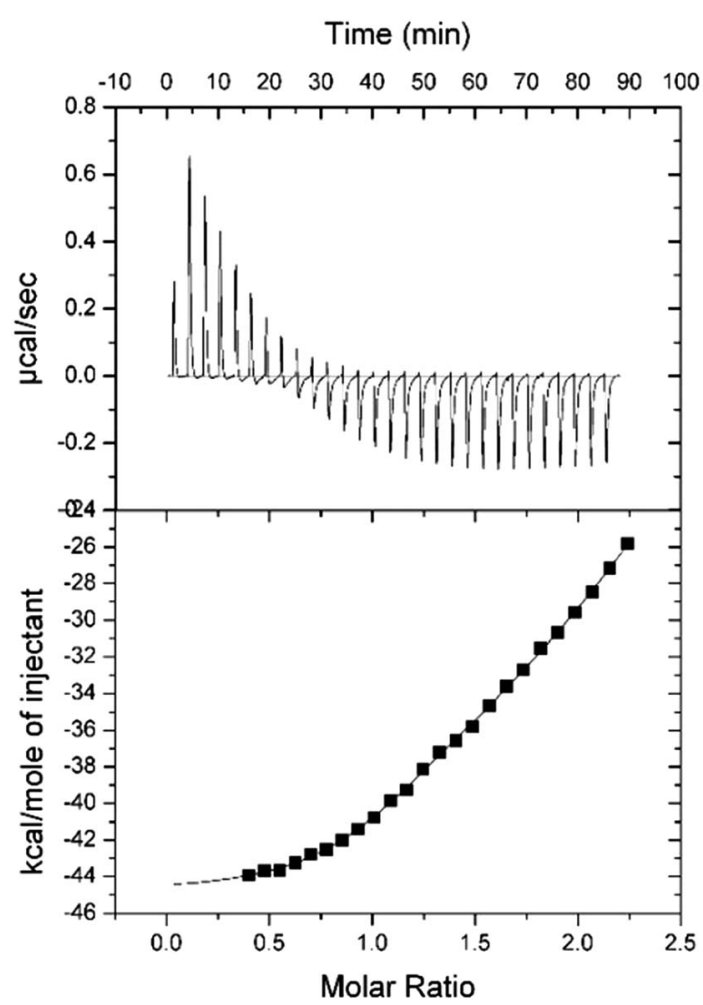

Fig. 3S ITC plot obtained from injection of $\mathrm{Zn}(\mathrm{Cys})_{2}$ complex into the micellar CTAB/SDS solution after subtraction of the buffer diluting plot.

Table 3S Thermodynamic parameters obtained from ITC

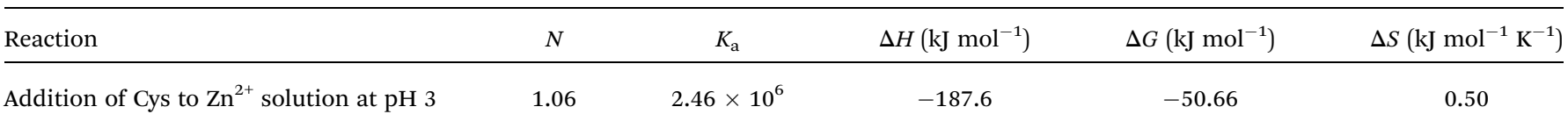


As a result of the above changes, the $\Delta H$ value reported in the sentence beginning "These results show that $\mathrm{Zn}$ complex has a strong interaction..." in the main article is also herein revised to $\Delta H=-187.6 \mathrm{~kJ} \mathrm{~mol}^{-1}$.

The author would also like to amend the Acknowledgements section; an updated version is therefore included below.

The Royal Society of Chemistry apologises for these errors and any consequent inconvenience to authors and readers.

\section{Acknowledgements}

This work was supported by Institute for Research in Fundamental Sciences and Support from the University of Tehran is gratefully acknowledged. I also thank Professor A. A. Moosavi Movahedi, Professor A. A. Saboury and Professor A. Shockravi. 